\title{
Original Research \\ Use of non-formulary drugs in children at a Brazilian teaching hospital: a descriptive study
}

\author{
Mariana Y. TRAMONTINA, Isabela HEINECK, Luciana DOS SANTOS \\ Received (first version): 9-Mar-2012 \\ Accepted: 1-Feb-2013
}

\begin{abstract}
${ }^{*}$
Objectives: To characterise the prescription of nonformulary drugs to children and neonates at a Brazilian teaching hospital and identify adverse drug reactions (ADRs), drug interactions, and prescription of potentially hazardous medicines. Methods: A prospective exploratory study was carried out between January and May 2011 at the general paediatric wards and paediatric oncology, paediatric intensive care, and neonatal care units of the study hospital. Non-formulary drugs were categorised as approved, off-label, or not approved for use in children according to Brazilian compendia. Electronic health records were actively searched for ADRs and the possibility of moderate to severe interactions between non-formulary drugs and other medicines was determined with the Micromedex® database.

Results: Overall, 109 children or neonates received non-formulary drugs. Of these drugs, $54 \%$ were approved for use in children, $12.2 \%$ were used offlabel, and $33.8 \%$ were not approved for use in children. Non-formulary drugs accounted for $13.4 \%$ of total prescriptions; $5.3 \%$ of drugs had a potential for interactions and five were possibly associated with ADRs.

Conclusion: Prescription of non-formulary drugs not approved for use in children was common at the study hospital. Studies such as this provide information on the use of medicines for special indications and permit assessment of the relevance of hospital formularies for the paediatric population.
\end{abstract}

Keywords: Drug Utilization Review; Off-Label Use; Inpatients; Child; Brazil

\author{
USO DE MEDICAMENTOS EXTRA- \\ FORMULARIO EN NIÑOS EN UN \\ HOSPITAL UNIVERSITARIO BRASILEÑO: \\ ESTUDIO DESCRIPTIVO
}

\section{RESUMEN}

Objetivos: Caracterizar la prescripción de medicamentos extra-formulario en niños y neonatos en un hospital universitario brasileño e identificar las reacciones adversas (RAM), interacciones y prescripción de medicamentos potencialmente peligrosos.

Métodos: Se realizó un estudio prospectivo exploratorio entre enero y mayo de 2011 en el servicio general de pediatría, oncología pediátrica y cuidados intensivos pediátricos del hospital en estudio. Los medicamentos extra-formulario se clasificaron en autorizados, off-label o no autorizados para uso en niños de acuerdo con el vademécum brasileño. Se buscó activamente en las historias clínicas electrónicas RAM y se determinó la posibilidad de interacciones moderadas o severas entre los medicamentos extra-formulario y otros medicamentos usando la base de datos

Micromedex®.

Resultados: En total 109 niños o neonatos recibieron medicamentos extra-formulario. De estos medicamentos, el 54\% estaban autorizados para uso en niños, el $12,2 \%$ eran off-label y el $33,8 \%$ no estaban autorizados para uso en niños. Los medicamentos extra-formulario representaron el 13,4\% del total de prescripciones; el 5,3\% tuvo potenciales interacciones y 5 estuvieron posiblemente asociados a RAM.

Conclusión: La prescripción de medicamentos extra-formulario no autorizados para uso en niños fue común en el hospital analizado. Estudios como este proporcionan información sobre el uso de medicamentos para indicaciones especiales y permiten evaluar la relevancia de los formularios hospitalarios para la población pediátrica.

Palabras clave: Revisión de la Utilización de Medicamentos; Uso Fuera de lo Indicado; Pacientes Internos; Niño; Brasil

\section{INTRODUCTION}

do Rio Grande do Sul; and Clinical Pharmacy Service, Hospital de Clínicas de Porto Alegre - HCPA. Porto Alegre (Brazil).

Isabela HEINECK. Programa de Pós-Graduação em Assistência Farmacêutica, Faculty of Pharmacy, Universidade Federal do Rio Grande do Sul. Porto Alegre (Brazil).

Luciana DOS SANTOS. Clinical Pharmacy Service, Drug Information Centre, Hospital de Clínicas de Porto Alegre HCPA. Porto Alegre (Brazil).
Throughout the various stages of development, paediatric patients exhibit differences in hepatic and renal function due to the gradual maturation of these systems over time. These differences affect the pharmacokinetics of medicines and, consequently, their effects. This biological immaturity, coupled with individual predispositions, 
hypersensitivities, and to the presence of polypharmacy in the hospital environment, exposes patients to such risks as lack of therapeutic effectiveness, development of adverse drug reactions (ADRs), drug-drug interactions, and toxicity. ${ }^{1,2}$

In a hospital setting, the selection of drugs by Pharmacy and Therapeutics Committees on the basis of scientific evidence of safety and efficacy contributes to the safe and rational use of medicines, particularly in children. The prescription of drugs not selected by Pharmacy and Therapeutics Committees for use in the hospital, or non-formulary drugs, encourages unapproved and off-label uses and may lead to unexpected events. Furthermore, the lack of information on the use and effects of medicines in paediatric populations contributes to medication errors. ${ }^{3}$

Despite well-known risks, the use of unlicensed drugs or use of licensed drugs for off-label indications is very common in children receiving oncologic or critical care. This is due to the highly restricted number of pharmaceutical forms available and to the lack of officially accepted scientific evidence for dosing choices in the paediatric population. ${ }^{4}$ These practices may pose risks to the patients, as they entail the use of medicines for which there are no defined parameters of efficacy and safety in children. In some cases, use is justified by the scientific evidence, but there is no financial interest in conducting studies or pursuing marketing authorisation from regulatory agencies. ${ }^{5}$

In the United States, roughly $80 \%$ of drugs prescribed to children are for indications not approved by the Food and Drug Administration (FDA). ${ }^{6}$ In Europe, only $35 \%$ of commercially available medicines are licensed for use in children.7 In Brazil, previous studies have reported a high prevalence of off-label use and use of unlicensed medications in hospitalized children. ${ }^{8-10}$ Cuzzolin et al. (2006) found that use of medicines in the aforementioned conditions is most common in neonatal, paediatric intensive care, and paediatric oncology units. ${ }^{11}$

There are studies that suggest the use of unlicensed drugs is related to the development of adverse reactions. Bonatti and Clavenna (2009) found that hospitalised children who had received drugs not licensed for paediatric use at some point during their hospital stays were 3.6 times more likely to develop an adverse reaction than children who had not been given such medicines. ${ }^{12}$ Of all paediatric patients, neonates are at the highest risk of developing ADRs, due to the physiological immaturity, low body weight, polypharmacy, and severe disease states associated with preterm birth. ${ }^{13}$

The main objective of this study was to characterise the prescription of non-formulary drugs to children and neonates in a teaching hospital in Southern Brazil, classifying them as licensed, off-label and unlicensed. Furthermore, identify potential adverse drug reactions, drug interactions, and patient hazards associated with the use of these medicines.

\section{METHODS}

This prospective exploratory study was carried out between January and May 2011 in the general paediatric ward, paediatric intensive care, paediatric oncology, and neonatal care units of a universitybased tertiary referral hospital in the South of Brazil. The study included paediatric patients who were given drugs not included in the hospital formulary after assessment by the local Pharmacy and Therapeutics Committee. This 795-bed hospital has a 47-bed neonatal care unit, for inpatient treatment of infants younger than 30 days, and an 89-bed paediatrics service, which includes an 18-bed paediatric oncology ward. Patients treated at or admitted from the emergency department were not included in the sample.

Patients who received non-formulary drugs were identified daily through the hospital's electronic records. Patient profiles and prescribing patterns were characterised from the information available on electronic records, clarified as necessary by consulting with the attending professionals. All drugs used were recorded by their Brazilian Nonproprietary Names and categorised according to the Anatomical Therapeutic Chemical (ATC) Classification System. Due to the heterogeneity of ages, patients were classed into age groups according to U.S. FDA guidelines: neonates (0-27 days), infants (28 days-23 months), children (2-11 years), and adolescents (12-18 years). ${ }^{14}$

Each prescription involving a non-formulary drug and other medicines was checked once for potential drug-drug interactions with the aid of the Micromedex ${ }^{\circledR}$ database. ${ }^{15}$ The potential for patient harm was assessed by checking the Institute for Safe Medication Practices (ISMP) List of High-Alert Medications. It's a list of drugs considered potentially dangerous because they pose risk of significant harm to patients when used inappropriately. ${ }^{16}$

Information on the approval status of non-formulary drugs for use in children was obtained from the electronic medicines compendium of the National Health Surveillance Agency and the Dicionário de Especialidades Farmacêuticas, Brazilian compendia that provide data on all medicines marketed in the country. Medications licensed for use in the study population were considered "approved" when prescribed according to the recommendations of the aforementioned compendia. Prescription of "approved" drugs at non-official doses or for ages and indications not mentioned in the official information was considered "off-label use". Imported drugs, those contraindicated in children, and those whose summaries of product information cite an absence of safety and efficacy data in children were considered "unlicensed", as were those approved for use in children but whose dosage forms were modified at the hospital pharmacy or by hospital nurses before administration. ${ }^{47-19}$ Extemporaneously compounded medicines were excluded from this classification, which was designed to apply only to commercially available medicinal products. 


\begin{tabular}{|c|c|}
\hline Patients $(n=109)$ & $\mathrm{N}(\%)$ \\
\hline $\begin{array}{r}\text { Male } \\
\text { Female }\end{array}$ & $\begin{array}{c}64(58.7) \\
45(41.3)\end{array}$ \\
\hline $\begin{array}{r}0-27 \text { days } \\
28 \text { days-23 months } \\
2-11 \text { years } \\
12-18 \text { years }\end{array}$ & $\begin{array}{c}7(6.4) \\
37(33.9) \\
40(36.7) \\
25(22.9)\end{array}$ \\
\hline Mean age (years) & $6(\mathrm{SD}=5.7)$ \\
\hline $\begin{array}{rr}\text { Inpatient unit } & \text { General ward } \\
\text { Oncology } \\
\text { Intensive care } \\
\text { Neonatal care }\end{array}$ & $\begin{array}{l}45(41.3) \\
30(27.5) \\
20(18.3) \\
14(12.8)\end{array}$ \\
\hline $\begin{array}{l}\text { Reason for admission/ } \\
\text { Affected system } \quad \text { Cancer } \\
\text { Respiratory } \\
\text { Premature birth } \\
\text { Gastrointestinal } \\
\text { Other }\end{array}$ & $\begin{array}{l}33(30.3) \\
15(13.8) \\
15(13.8) \\
9(8.3) \\
37(33.8)\end{array}$ \\
\hline Total & $109(100)$ \\
\hline
\end{tabular}

Patients who received non-formulary drugs were followed throughout the treatment course, for a maximum of 30 days or until hospital discharge, for monitoring of adverse reactions. An active search for ADRs was carried out daily. When ADRs were detected, the Naranjo algorithm was used to establish a causal relationship between the suspected drug and suspected reaction, classifying the latter as definite, probable, possible, or doubtful. It consists of a structured questionnaire with 10 questions that guide the assessment of the relationship between cause and effect between a drug and events. ${ }^{20}$ ADRs were also categorised as predictable (Type A) or idiosyncratic (Type B), according to Rawlins and Thompson. ${ }^{21}$

Patient and drug data were stored in a Microsoft Excel database, processed, and analysed with the SPSS 18.0 software. Statistical analysis was descriptive (absolute and relative frequencies and means and standard deviations).

The study was approved by the Hospital de Clínicas de Porto Alegre Research Ethics Committee.

\section{RESULTS}

During the study period, 109 patients received nonformulary drugs and were monitored. Mean length of stay was 53.7 days $(S D=114.8)$. A profile of patients is shown in Table 1.

Overall, 1260 drugs were prescribed, for a mean 11.5 drugs per prescription (SD=6.3). Non-formulary drugs accounted for $13.4 \%$ of these, with a mean 1.5 non-formulary products prescribed for each patient. Of these, $41.4 \%$ were prescribed to patients in the general paediatric ward, $24.9 \%$ to patients in the oncology service, $17.7 \%$ to patients in intensive care, and $16 \%$ to infants in the neonatal unit.

Prescription of non-formulary drugs was most common in the 2 to 11 year age group, which corresponded to approximately $37 \%$ of patients. Of the various non-formulary drugs prescribed, $4.7 \%$ (alteplase, dexmedetomidine, cladribine, melphalan, and topotecan) were considered potentially hazardous due to inclusion in the ISMP list of HighAlert Medications, and 5.3\% (aprepitant, chlortalidone, fluoxetine, foscarnet, olanzapine, and sotalol) had a potential for moderate or severe interactions with one or more drugs prescribed concomitantly.

A profile of the most commonly prescribed nonformulary drugs is shown in Table 2. Of all nonformulary drugs, approximately $79 \%$ were started during the hospital stay, and $38.5 \%$ had already been used by the patient during previous admissions. The average duration of non-formulary drug use was 4.4 days (range, 1-37 days). This calculation did not include patients who received a single dose of a non-formulary drug (17 patients), those who were on chronic therapy with such drugs (31 patients), and those who were prescribed such drugs for an indeterminate period (9 patients).

Regarding marketing authorisation for use in children, 80 (54\%) drugs were considered "approved", taking into account the therapeutic indication, age group, and dosage. Off-label use and unlicensed medicines accounted for $12.2 \%$ and $33.8 \%$ of non-formulary drug prescriptions respectively. Extemporaneously compounded preparations, which were not included in our analysis, accounted for $12.4 \%$ of non-formulary drug prescriptions (21 drugs).

Of the 18 drugs used off-label, 15 (83.3\%) were thus classified because the prescribed dose was lower or higher than that recommended in the summary of product characteristics. The lack of scientific evidence of efficacy and safety in children $(82 \%)$ and the use of imported medicines (10\%) were the leading reasons for classification of nonformulary drugs as "unlicensed" for use in children.

\begin{tabular}{|l|l|c|c|c|c|}
\hline \multicolumn{1}{|c|}{ Table 2- Most commonly used non-formulary drugs. } & \multicolumn{1}{|c|}{ Class/ATC } & $\begin{array}{c}\text { High alert } \\
\text { medication }\end{array}$ & Reason for use & $\begin{array}{c}\text { Drug-drug } \\
\text { interactions }\end{array}$ & $\begin{array}{c}\text { Total } \\
(\%)\end{array}$ \\
\hline DTaP vaccine & Vaccines/J07 & No & Immunization & No & 6,6 \\
\hline Inactivated polio vaccine & Vaccines/J07 & No & Immunization & No & 6,0 \\
\hline $\begin{array}{l}\text { 10-valent pneumococcal } \\
\text { conjugate vaccine }\end{array}$ & Vaccines/J07 & No & Immunization & No & 6,0 \\
\hline Palonosetron & Antiemetics/A04 & No & Antiemetic & No & 6,0 \\
\hline Aprepitant & Antiemetics/A04 & No & Antiemetic & $\begin{array}{c}\text { Yes } \\
\text { (dexamethasone, } \\
\text { fentanyl) }\end{array}$ & 6,0 \\
\hline Vitamin C & Vitamins/A11 & No & Supplementation & No & 4,2 \\
\hline Meningitis C vaccine & Vaccines/J07 & No & Immunization & No & 3,6 \\
\hline Amphotericin B lipid formulation & $\begin{array}{l}\text { Antimycotics for } \\
\text { systemic use/J02 }\end{array}$ & No & $\begin{array}{c}\text { Systemic fungal } \\
\text { infection }\end{array}$ & No & 3,6 \\
\hline
\end{tabular}


Tramontina MY, Heineck I, Dos Santos L. Use of non-formulary drugs in children at a Brazilian teaching hospital: a descriptive study. Pharmacy Practice 2013 Jan-Mar;11(1):17-23.

\begin{tabular}{|c|c|c|c|c|c|c|}
\hline Drug & ATC & Route & Age* & Dose* & Indication* & $\begin{array}{c}\text { Total } \\
\mathrm{N}(\%)\end{array}$ \\
\hline Vitamin C & A11GA01 & Oral & 1 & 2 (below recommended) & 1 & $7(38.9)$ \\
\hline Sodium valproate & N03AG01 & Oral & 1 & 2 (above recommended) & 1 & $1(5.5)$ \\
\hline Ciprofloxacin & S03AA07 & Ophthalmic & 2 & 2 (above recommended) & 1 & $1(5.5)$ \\
\hline Fluticasone & R01AD08 & Nasal & 2 & 1 & 2 & $1(5.5)$ \\
\hline
\end{tabular}

Sixty-one patients $(56 \%)$ received unlicensed or offlabel medications during their hospital stay, with 42 (38.5\%) receiving at least one drug not approved for use in children and $19(16.5 \%)$ given at least one drug off-label. A profile of the most commonly prescribed unlicensed and off-label drugs is shown in Tables 3 and 4.

During the study period, 169 (13.4\%) non-formulary drugs were assessed and cleared for use in patients under the age of 18 by the hospital's Pharmacy and Therapeutic Committee. According to hospital data, the rate of non-formulary drug prescription in adult and paediatric patients ranged from $0.6 \%$ to $0.8 \%$ between 2007 and 2010, with an average rate of $0.68 \%$. Approximately $80 \%$ of non-formulary drugs prescribed were ultimately cleared for use, with $10 \%$ of these prescribed to children.

The most commonly prescribed classes of nonformulary drugs were immunobiologicals (vaccines), antiemetics, vitamins, psychotropic drugs, beta blockers, and systemic antimycotics and antibacterials. Vaccines accounted for approximately $30 \%$ of all requests, as a substantial portion of the sample was composed of neonates and infants, who, as an age group, receive the most immunizations. The most commonly prescribed vaccines were the inactivated polio vaccine; the diphtheria, tetanus, pertussis (acellular, component) vaccine (DTaP); and the 10-valent pneumococcal conjugate vaccine, all of which are recommended by the Brazilian Ministry of Health. ${ }^{22}$ Palonosetron and aprepitant, two antiemetics indicated for the prevention of chemotherapy-induced nausea and vomiting in cancer patients, accounted for $13 \%$ of non-formulary drug prescriptions. These antiemetics were used instead of formulary ones because they promote greater therapeutic gain for patients to whom these drugs were prescribed, according to medical judgment.

Several studies have reported that systemic antimicrobials are the class of drug most commonly used off-label. ${ }^{13,23,24}$ In this study, imipenem with cilastatin was prescribed above the maximum recommended daily dose of $2 \mathrm{~g}$ (approximately 3.5 g administered); conversely, amphotericin B lipid formulation was prescribed at a dose below the recommended minimum. The use of vitamin $C$ in neonates was also considered off-label, as the prescribed dose was below the recommended minimum of $30 \mathrm{mg}$ daily; however, this particular use was not considered inappropriate, as it is a vitamin supplement and poses no threat of patient harm. In terms of indication, the use of sodium valproate (divalproate) for treatment of encephalopathy was considered off-label, as this drug is only approved for paediatric use in the treatment of epilepsy, and in children aged 10 or older.

Throughout the study period, the only non-formulary drug whose dosage form was extemporaneously altered was oseltamivir phosphate, which was prescribed for influenza A prophylaxis and accounted for $1.8 \%$ of all non-formulary drug prescriptions.

Checks of non-formulary drug prescriptions against the Micromedex $®$ database revealed few drug-drug interactions, all of which were classified as moderate. Such interactions are usually managed by means of dosage adjustments or by spacing out administration of the involved drugs. Examples of drug interactions in this study include the concomitant use of sotalol and ibuprofen (in one out of nine patients with potential interactions), which can blunt the antihypertensive effect of sotalol, and the concomitant use of olanzapine and sodium valproate (in one out of nine patients with potential interactions), which reduces serum levels of olanzapine.

Five of the monitored patients (4.6\%) had symptoms suggestive of an ADR induced by the prescribed non-formulary drug: two patients in the general paediatric ward, two in the oncology ward, and one in intensive care. Five ADRs were identified; two of these (40\%) were associated with the use of an unlicensed drug, and none could be ascribed to off-label use of a non-formulary drug. The mean duration of follow-up in these patients was 7 days (range, 1-30 days). Table 5 lists the drugs involved in suspected ADRs.

Attempts to associate the presence of ADRs with unlicensed and off-label prescribing showed no statistically significant between-group difference.

\section{DISCUSSION}

The Pharmacy and Therapeutic Committee of the hospital in which this study was conducted, a multidisciplinary panel of pharmacists, physicians,

\begin{tabular}{|l|l|c|}
\hline \multicolumn{1}{|c|}{ Table 4 - Non-formulary drugs not licensed for use in children. } & $\mathrm{N}(\%)$ \\
\hline \multicolumn{1}{|c|}{ Drugs ( $\mathrm{n} \%)$} & Reason for unlicensed status & $41(82.0)$ \\
\hline $\begin{array}{l}\text { Aprepitant, aripiprazole. cladribine, dexmedetomidine, } \\
\text { flunarizine, fluoxetine, melphalan, nitroglycerin, olanzapine, } \\
\text { palonosetron, sotalol, tizanidine, topotecan }\end{array}$ & Safety and efficacy not established & \\
\hline Alteplase, factor VIII, foscarnet, pancrelipase & Product not available (imported drug) & $5(10.0)$ \\
\hline Oseltamivir & Change in pharmaceutical form & $3(6.0)$ \\
\hline Sildenafil & Contraindicated & $1(2.0 \%)$ \\
\hline
\end{tabular}


Tramontina MY, Heineck I, Dos Santos L. Use of non-formulary drugs in children at a Brazilian teaching hospital: a descriptive study. Pharmacy Practice 2013 Jan-Mar;11(1):17-23.

\begin{tabular}{|c|c|c|c|c|c|}
\hline Suspected drug & $\begin{array}{l}\text { Approval } \\
\text { status }\end{array}$ & Description of ADR & Causality & Predictability & Management \\
\hline Acitretin & Approved & Hypomagnesaemia & Probable & A & $\begin{array}{l}\text { Continuation of } \\
\text { treatment/ magnesium } \\
\text { replacement }\end{array}$ \\
\hline $\begin{array}{l}\text { Amphotericin B lipid } \\
\text { formulation }\end{array}$ & Approved & Rigors & Probable & B & Diphenhydramine \\
\hline Cladribine & Unlicensed & Anorexia & Probable & A & $\begin{array}{l}\text { Continuation of } \\
\text { treatment }\end{array}$ \\
\hline Dexmedetomidine & Unlicensed & Periorbital oedema & Probable & B & $\begin{array}{l}\text { Continuation of } \\
\text { treatment; dose } \\
\text { reduction; eventual } \\
\text { discontinuation. }\end{array}$ \\
\hline $\begin{array}{l}\text { Vaccines } \\
\text { (DTaP/inactivated polio } \\
\text { vaccine/ haemophilus B } \\
\text { vaccine) }\end{array}$ & Approved & Hyperthermia & Probable & A & Paracetamol \\
\hline
\end{tabular}

and nurses, is responsible for selecting drugs for inclusion in the hospital formulary and appraising requests for medications not included in this formulary. Therefore, issues such as therapeutic indication, dosage, and cost-benefit considerations are assessed before the drug is cleared, or declined, for use. The use of non-formulary drugs is a concerning practice, especially in children, due to the lack of formulations available for easier dosage adjustments and to the risk of empirical use of adult medications for which no paediatric safety data are available.

Unlicensed and off-label prescribing is usually attributed to a lack of clinical trials in the paediatric population, due to high heterogeneity in pharmacokinetic parameters and ethico-legal issues for research. ${ }^{1,8}$ These prescribing practices are legal in most countries, and often constitute the most adequate treatment or, in some cases, the only alternative for the receiving patient. ${ }^{17}$

Regarding licence status, the findings of this study diverge from those of other investigations, in which off-label use was more common than prescription of unlicensed drugs. In a study of children in the same age range, Santos et al. (2008) found that $39.6 \%$ of medications were used off-label, and $5.5 \%$ of prescriptions were of drugs not approved for use in children. $^{8}$ A prior study conducted in a sample of patients between the ages of 0 and 14 years admitted to the general paediatric ward of our facility found that, out of 2026 formulary drugs prescribed between November 2007 and January $2008,38.9 \%$ were used off-label and $11.8 \%$ were unlicensed for use in children. Of all prescription drugs, 49 drugs (2.4\%) were not part of the list of formulary ones. ${ }^{10}$

One possible reason why use of unlicensed drugs was more common than off-label use in our sample is the fact that these medicines have only recently become available on the market; therefore, their therapeutic indications and dosage and administration data are restricted to those determined in adult clinical trials and filed while applying for marketing authorisation from the National Health Surveillance Agency. The antiemetics palonosetron and aprepitant, for instance, are not licensed by regulatory authorities for use in children, as there are no definite efficacy and safety data for paediatric populations. However, recent scientific evidence supports their use. Sepúlveda-Vildósola et al. found that palonosetron is a useful alternative to ondansetron (a formulary drug at the study hospital) in paediatric oncology patients in terms of cost, efficacy, and the complete absence of adverse reactions throughout the study period. ${ }^{25}$ As for aprepitant, a randomised doubleblind clinical trial of oncology patients between the ages of 11 and 19 found the combination of aprepitant, dexamethasone, and ondansetron to be well-tolerated and associated with increased treatment efficacy as compared with a control group that received dexamethasone and ondansetron alone. There were no significant between-group differences. According to the authors, this was most likely due to the small sample size. ${ }^{26}$

Among paediatric patients, those receiving oncologic care are usually the leading recipients of unlicensed or off-label medicines, due to the physiological conditions inherent to childhood, to the malignant nature of their diseases, and to ethical issues. Van den Berg and Tak (2011) found that $87 \%$ of patients admitted to a paediatric oncology ward received at least one unlicensed medicine over a 2-week period; $43 \%$ of these prescriptions were categorised as off-label use. ${ }^{27}$ A UK study reported a $45 \%$ rate of unlicensed or off-label prescriptions in the study population. ${ }^{28}$

Also with respect to off-label use, dosage is cited as the most common reason for classifying prescriptions into this category. ${ }^{8,19,22}$ However, O'Donnell et al. (2002) claim therapeutic indications, which often differ from approved ones, are the most common reason for off-label use. ${ }^{29}$ In this sample, the incidence of off-label prescribing was highest in the general paediatric ward and neonatal care unit; this is consistent with the literature. ${ }^{8,9,11}$

't Jong et al., O'Donnell et al., and Hsien et al. found that modification of dosage forms to allow or facilitate use in paediatric patients is a very common practice. It may, however, lead to changes in pharmacokinetic parameters, and is thus considered unlicensed use. ${ }^{19,24,29}$ In our facility, oseltamivir was modified, even though an oral suspension is commercially available for use in children aged 1 year or over. An oral preparation was extemporaneously prepared from oseltamivir capsules, as recommended by the Brazilian Ministry of Health, due to temporary unavailability of the oral 
suspension during an influenza epidemic. In this particular case, instructions for compounding of oral solution were provided by the product manufacturer, but no information is available for the majority of extemporaneous oral preparations.

Regarding drug interactions, in addition to harmful interactions, which antagonise the desired pharmacological effects or augment them excessively, some interactions also improve response to therapy or reduce the incidence of adverse effects due to concomitant use. Over the course of this study, several therapeutically beneficial interactions were observed, such as the combination of dexamethasone and aprepitant, which improves control of chemotherapy-induced nausea and vomiting, and the combination of chlortalidone and captopril, which, thanks to its additive effects, improves control of hypertension.

Unlicensed or off-label use is known to contribute to an increase in the incidence of adverse reactions in paediatric inpatients, which can range from $1.5 \%$ to $20 \%{ }^{12}$ In a 2008 study of 160 hospitalised children receiving medicines off- label, a total of 34 adverse reactions occurred in $26(16.3 \%)$ patients, for an ADR incidence rate of $12.5 \%{ }^{8}$ Gil et al. (1995) identified 76 adverse reactions in a sample of 899 patients admitted to a paediatric intensive care unit, and found that, of the 35 drugs involved, 25 (71.4\%) were used off-label with respect to age, dose, or indication and one (4\%) was not licensed for use in children. ${ }^{30}$ A review by Santos and Coelho (2004) showed that the incidence of adverse reactions in paediatric patients is directly related to the number of drugs administered and to the length of hospital stay. The incidence of ADRs was highest in the 0 to 24 month age range and in female patients. ${ }^{31}$ The studies analysed in this review considered drugs included in the formularies of the hospitals where they were carried out.

The number of adverse reactions detected was low due to the small number of patients in the study and to under-reporting. ADR detection also depends on the involvement of health professionals and on the type of reaction; more overt ADRs, such as those affecting the gastrointestinal or integumentary system, are diagnosed more often. It is estimated that approximately $6 \%$ of ADRs are reported through spontaneous notification schemes. ${ }^{32,33}$

The use of potentially hazardous, or "High-Alert", medications predisposes to the development of adverse drug reactions, particularly in children. These drugs are more likely to cause patient harm due to their frequent involvement in medication errors, which requires more intensive monitoring by attending professionals. According to the Institute of
Health Care Improvement, approximately 58\% of cases of medication-induced harm in the hospital setting are associated with high-alert medications. ${ }^{10}$ Silva et al. (2011) found that approximately $34 \%$ of prescriptions from the paediatric ward of a Brazilian university hospital contained one or more ISMP High-Alert Medications. Overall, 705 such drugs were prescribed and dispensed over the 30-day study period; they were involved in at least one dispensing error and $89.6 \%$ were involved in prescribing errors. The authors suggest that prescription quality is a predisposing factor for dispensing errors, in view of the strong statistical association $(p<0.0001)$ between these variables. The main reported sources of error are dosage, frequency of administration, dilution, and drug name. $^{34}$

This study had the following limitations: a maximum follow-up period of 30 days, thus precluding detection of delayed ADRs; under-reporting of ADRs, which fails to reflect the true incidence of these reactions; study duration, as patients enrolled near the end of the data collection period only had partial follow-up; and small sample size, as the study only included patients who had received nonformulary drugs. Despite these limitations, this investigation is valid in that it can provide inputs to support some actions concerning non-formulary drugs.

\section{CONCLUSIONS}

Much of paediatric pharmacotherapy is based on extrapolation of the data used to grant marketing authorisation for use of medicines in adults. Due to the lack of scientific evidence of safety and efficacy in children, significant non-formulary drugs are unlicensed for used in paediatric populations. Studies have shown that unlicensed and off-label prescription is associated with the development of adverse reactions. Furthermore, these practices may lead to drug interactions and medication errors. Therefore, Pharmacy and Therapeutics Committees play an important role in appraising and selecting medicines for inclusion in hospital formularies, particularly for use in children, as do hospital pharmacists, by monitoring medication use and protecting patient safety.

\section{CONFLICT OF INTEREST}

The authors declare no conflict of interests.

Funding: Fundo de Incentivo à Pesquisa, Hospital de Clínicas de Porto Alegre (FIPE-HCPA)

1. Napoleone E. Children and ADRs (Adverse Drug Reactions). Ital J Pediatr. 2010;36:4. doi: 10.1186/1824-7288-36-4.

2. Brassica, SC. O Papel do Farmacêutico na Utilização de Medicamentos Não Aprovados e em Indicações Não Licenciadas. In: Farmácia Clínica e Atenção Farmacêutica (Guanabara Koogan,ed), Rio de Janeiro. 2008; p.221-5

3. Ribeiro E, Takagi CA. Seleção de Medicamentos. In: Farmácia Clínica e Atenção Farmacêutica (Guanabara Koogan, ed), Rio de Janeiro. 2008; p.136-44

4. Kairuz TE, Gargiulo D, Bunt C, Garg S. Quality, Safety and Efficacy in the 'Off-Label' Use of Medicines. Curr Drug Saf. 2007;2(1):89-95. 
5. Delgado O, Puigventós F, Clopés A. [Position of the hospital pharmacist regarding the use of medication in nonauthorised conditions]. Farm Hosp. 2009;33(5):237-9.

6. Macaulay TE, Cook AM, Fink JL 3rd, Rapp RP, Vincent WR 3rd. Pharmacists' role in facilitating evidence-based prescribing for unlabeled use of medications. Am J Health Syst Pharm. 2009;66(19):1735-9. doi: 10.2146/ajhp080352.

7. Boots I, Sukhai RN, Klein RH, Holl RA, Wit JM, Cohen AF, Burggraaf J. Stimulation Programs for Pediatric Drug Reserch - Do Children Really Benefit? 2007; Eur J Pediatr. 2007;166(8):849-55.

8. Santos DB, Clavenna A, Bonati M, Coelho HL. Off-label and unlicensed drug utilization in hospitalized children in Fortaleza, Brasil. Eur J Clin Pharmacol. 2008;64(11):1111-8. doi: 10.1007/s00228-008-0543-1.

9. Carvalho PR, Carvalho CG, Alievi PT, Martinbiancho J, Trotta EA. Prescription of Drugs not Appropriate for Children in a Pediatric Intensive Care Unit. J Pediatr (Rio J). 2003;79(5):397-402.

10. Dos Santos L, Heineck I. Drug Utilization Study in Pediatric Prescriptions of a University Hospital in Southern Brazil: Offlabel, Unlicensed and High-alert Medications. Farm Hosp. 2012;36(4):180-6. doi: 10.1016/j.farma.2010.12.008.

11. Cuzzolin L, Atzei A, Fanos V. Off-label and unlicensed prescribing for newborns and children in different settings: review of the literature and a consideration about drug safety. Expert Opin Drug Saf. 2006;5(5):703-18.

12. Clavenna A, Bonati M. Adverse drug reactions in childhood: a review of prospective studies and safety alerts. Arch Dis Child. 2009;94(9):724-8. doi: 10.1136/adc.2008.154377.

13. Dell'Aera M, Gasbarro AR, Padovano M, Laforgia N, Capodiferro D, Solarino B, Quaranta R, Dell'Erba AS. Unlicensed and off-label use of medicines at a neonatology clinic in Italy. Pharm World Sci. 2007;29(4):361-7.

14. Food and Drug Administration (2000) Guidance for industry E11. Clinical investigation of medicinal products in the pediatric population. Food and Drug Administration, Center for Drug Evaluation and Research (CDER), Center for Biologies Evaluation an Reasearch (CBER), p. 9-12.

15. Drugdex - Micromedex Healthcare series. V. 1.0. New York: Thomson Healthcare, Inc. 1974-2010. Available at http://www.portaldapesquisa.com.br/databases/sites (Access: 1 May 2011).

16. Institute for Safe Medication Practices (2008); Lista de Medicamentos Potencialmente. Perigosos. Available at http//www.ismp.org/Tools/highalertmedications.pdf (Access: 1 Oct. 2010).

17. Conroy S, McIntyre J. The use of unlicensed and off-label medicines in the neonate. Semin Fetal Neonatal Med. 2005;10(2):115-22.

18. Conroy S, Choonara I, Impicciatore P, Mohn A, Arnell H, Rane A, Knoeppel C, Seyberth H, Pandolfini C, Raffaelli MP, Rocchi F, Bonati M, Jong G, de Hoog M, van den Anker J. Survey of unlicensed and off-label drug use in paediatric wards in European countries. BMJ. 2000;320(7227):79-82.

19. 't Jong GW, van der Linden PD, Bakker EM, van der Lely N, Eland IA, Stricker BH, van den Anker JN. Unlicensed and off-label drug in paediatric ward of a general hospital in the Netherlands. Eur J Clin Pharmacol. 2002;58(4):293-7.

20. Naranjo CA, Busto U, Sellers EM, Sandor P, Ruiz I, Roberts EA, Janecek E, Domecq C, Greenblatt DJ.A method for estimating the probability of adverse drug reaction. Clin Pharmacol Ther. 1981;30(2):239-45.

21. Rawlings MD, Thompson JW. Mechanism of adverse drug reactions. In: Davies DM, ed. Textbook of adverse drug reactions, 4th edn. Owford Oxford Medical publication , 1991: Chapter 3.

22. Brasil. Ministério da Saúde. Secretaria de Vigilância em Saúde. Departamento de Vigilância Epidemiológica. Manual dos centros de referência dos imunobiológicos especiais - Brasília: Ministério da Saúde, 2006. 188 p

23. Kimland $E$, Nydert $P$, Odlind $V$, Böttiger $Y$, Lindemalm $S$. Paediatric drug use with focus on off-label prescriptions at Swedish hospitals - a nationwide study. Acta Paediatr. 2012;101(7):772-8. doi: 10.1111/j.1651-2227.2012.02656.x.

24. Hsien L, Breddemann A, Frobel AK, Heusch A, Schmidt KG, Läer S. Off-label drug use among hospitalised children: identifying areas with the highest need for research. Pharm World Sci. 2008;30(5):497-502. doi: 10.1007/s11096-0089193-8.

25. Sepúlveda-Vildósola AC, Betanzos-Cabrera Y, Lastiri GG, Rivera-Márquez H, Villasis-Keever MA, Del Angel VW, Díaz FC, López-Aguilar E. Palonosetron Hydrochloride Is an Effective and Safe Option to Prevent Chemotherapy-induced Nausea and Vomiting in Children. Arch Med Res. 2008;39(6):601-6. doi: 10.1016/j.arcmed.2008.04.007.

26. Gore L, Chawla S, Petrilli A, Hemenway M, Schissel D, Chua V, Carides AD, Taylor A, Devandry S, Valentine J, Evans JK, Oxenius B; Adolescent Aprepitant in Cancer Study Group. Aprepitant in Adolescent Patients for Prevention of Chemotherapy-Induced Nausea and Vomiting: A Randomized, Double-Blind, Placebo-Controlled Study of Efficacy and Tolerability. Pediatr Blood Cancer. 2009;52(2):242-7. doi: 10.1002/pbc.21811.

27. van den Berg $\mathrm{H}$, Tak N.Licensing and labelling of drugs in a paediatric oncology ward. $\mathrm{Br} \mathrm{J}$ Clin Pharmacol. 2011;72(3):474-81. doi: 10.1111/j.1365-2125.2011.03977.x.

28. Conroy S, Newman C, Gudka S. Unlicensed and off-label drug use in acute lymphoblastic leukaemia and other malignancies in children. Ann Oncol. 2003;14(1):42-7.

29. O'Donnell CP, Stone RJ, Morley CJ. Unlicensed and off-label drug use in an Australian neonatal intensive care unit. Pediatrics. 2002;110(5):e52.

30. Gill AM, Leach $\mathrm{HJ}$, Hughes J, Barker C, Nunn AJ, Choonara I.Adverse drug reactions in a paediatric intensive care unit. Acta Paediatr. 1995;84(4):438-41.

31. Santos DB, Coelho HLL. Reações adversas a medicamentos em pediatria: uma revisão sistemática de estudos prospectivos. Rev Bras Saúde Matern Infant. 2004;4:341-9

32. Lopez-Gonzalez E, Herdeiro MT, Figueiras A. Determinants of Under-Reporting of Adverse Drug Reactions a Systematic Review. Drug Saf. 2009;32(1):19-31. doi: 10.2165/00002018-200932010-00002.

33. Castro-Pastrana LI, Carleton BC.Improving pediatric drug safety: need for more efficient clinical translation of pharmacovigilance knowledge. J Popul Ther Clin Pharmacol. 2011;18:e76-88.

34. Silva Md, Rosa MB, Franklin BD, Reis AM, Anchieta LM, Mota JA. Concomitant prescribing and dispensing errors at a Brazilian hospital: a descriptive study. Clinics (Sao Paulo). 2011;66(10):1691-7. 